\title{
A "realidade" no romance naturalista: questões teóricas de uma aproximação comparativa
}

\author{
Leandro Thomaz de Almeida ${ }^{1}$ \\ Instituto de Estudos da Linguagem da UNICAMP/ Bolsista FAPESP
}

Resumo: Parte-se aqui da obra romanesca de Inglês de Sousa (1853-1918) e de discussões suscitadas pela sua recepção crítica para discutir estratégias da composição literária de corte realista/naturalista e a pretensão de fidelidade entre a narração e seu objeto. Procuramos levar em consideração as contribuições provenientes dos trabalhos de Lilian Furst e Garry Potter para incrementar esse debate e lançar uma questão sobre o estatuto de verdade da prosa com essa característica.

Palavras-chave: Literatura naturalista. Inglês de Sousa. Representação.

Eu não faço comentários. Narro apenas o que sei.

Inglês de Sousa, História de um pescador

Faire vrai consiste donc à donner l'illusion complète du vrai, suivant la logique ordinaire des faits, et non à les transcrire servilement dans le pêle-mêle de leur succession. J'en conclus que les Réalistes de talent devraient s'appeler plutôt des Illusionnistes.

Guy de Maupassant, 'Prefácio' a Pierre et Jean

Poiesis is in realism masked as mimesis. Lilian Furst, All is true

\section{1}

Uma dicotomia ainda parece muito presente nos estudos de literatura. Um dos seus polos pode ser visto nos termos de Michael Riffaterre: "na verdade, referencialidade exterior é apenas uma ilusão, pois signos ou sistema de signos referem-se a outros sistemas de signos" (RIFFATERRE, 1990, p. 3). ${ }^{2}$ O outro está presente em abordagens muito comuns da literatura naturalista, como mostrarei adiante, que leem os romances de finais do século XIX como retratos fiéis da realidade que lhes serve de tema. Uma grande abstração desses dois polos diria que eles se traduzem em termos de uma aproximação estruturalista por um lado e mimética por outro, sugerindo que o antídoto para os problemas de uma abordagem fosse a pronta admissão da outra. Minha pretensão aqui não é a de propor um insosso meio termo

\footnotetext{
${ }^{1}$ Doutor em Teoria e História Literária pela Unicamp (2013) e pesquisador-colaborador do Instituto de Estudos da Linguagem da Unicamp. Bolsista FAPESP.

${ }^{2}$ As traduções, salvo indicação contrária, foram feitas pelo autor do artigo. 
entre as duas, mas explorar as possibilidades abertas pelo problema, tendo como alvo tanto o romance realista/naturalista quanto relatos de viajantes pela Amazônia na segunda metade do século XIX. Vale lembrar que, quanto ao uso dos termos realista e naturalista para se referir ao romance, tenho ciência de que não são sinônimos; a indistinção aqui presente, no entanto, tem a pretensão de apontar tão somente para certas características de romances da segunda metade do século XIX que almejaram criar um efeito de realidade, em contraposição ao que seriam fantasias românticas. Eles se inserem no que David Baguley chamou de "modo realista":

Para não nos aventurar e nos perder na floresta de inumeráveis definições do 'realismo', propomos simplesmente uma distinção fundamental entre o modo realista e o gênero realista. Vários gêneros literários recorreram às práticas textuais dessa modalidade, que consistem em tornar indissociáveis o discurso e a realidade que ele evoca. O 'modo realista' seria, então, transhistórico e transgenérico. Em contraste, o gênero realista tem sua própria periodização, com Balzac e Flaubert como principais marcos, e suas próprias constantes temáticas, como, notadamente, as esperanças, as aventuras e as decepções do indivíduo 'problemático' condenado a viver em um ambiente burguês e materialista. É evidente que, segundo essa distinção de base, a literatura naturalista poderia se definir como um gênero que explora plenamente as estratégias do 'modo realista' e se situa na continuidade do 'gênero realista', mas que assume, como veremos, sua própria combinação de temas e de práticas textuais (BAGULEY, 1995, p. 35).

Também não perco de vista que esse problema tem uma imensa fortuna crítica, abrangendo estudos clássicos como Mimesis, de Erich Auerbach e, no Brasil, parte considerável da obra de Antonio Candido e os numerosos comentários por ela suscitados. Não obstante, por situar minha questão no âmbito mais restrito da recepção crítica dos romances de Inglês de Sousa, e por não optar por uma discussão "pura" de teoria literária, não vou me deter em um levantamento da questão, impossível, aliás, no espaço aqui disponível, mas tão somente aproveitar, em um momento ou outro, alguns de seus aspectos.

Tomemos o caso da prosa ficcional de Herculano Marcos Inglês de Sousa (1853-1918), que ficou conhecido como autor de "romances amazônicos", tanto por haver nascido nessa região quanto por situar seus enredos no norte do Brasil. Apostar no estruturalismo desbragado em sua leitura seria ignorar que há uma realidade fora de seus romances. Quando escreve livros como O cacaulista (1876), O coronel Sangrado (1877), O missionário (1888), ele se refere a lugares que podem ser localizados fora das páginas da ficção, como a cidade de Óbidos, no Pará, os rios, as florestas e as tribos indígenas, os quais têm uma existência "real". Ler seus romances como se fossem um construto com tal grau de hermetismo em relação ao que é descrito, de modo que a nomeação de lugares reais não exerceria qualquer impacto 
sobre sua leitura, é optar por desconsiderar a ideia de que a produção ficcional quer ser alguma forma de intervenção no mundo; nesse caso, uma regulada justamente pela pretensão de transmitir um efeito de realidade. Como sugere Stephen Greenblatt, a literatura apresenta ao menos três modos de "funcionamento": "como uma manifestação do comportamento do seu autor, como expressão de códigos pelos quais o comportamento é moldado e como uma reflexão sobre esses códigos" (GREENBLATT, 2005, p. 4). O fato de um romance ser situado na Amazônia em finais do século XIX e procurar descrever com minúcias esse ambiente é um ato significativo também pelo entorno que envolve essa produção.

Por outro lado, no afã de enfatizar seu caráter descritivo, a crítica sobre os romances de Inglês de Sousa parece ter investido de tal modo na ideia de mímese como representação da realidade que o caráter construtivo e interpretativo da linguagem ficou em segundo plano. Não vou me deter em minúcias dessa abordagem, apenas apontar rapidamente alguns exemplos: Massaud Moisés falou de um aspecto testemunhal da prosa de Inglês de Sousa: "realista pelo verismo das cenas, pelo registro fidedigno, testemunhal, da ecologia amazonense, mas não pela intenção, e sem esta, a obra oscila entre o realismo-romântico e o Realismo propriamente dito” (MOISÉS, 2001, p. 48 - grifo do autor); Bella Josef tratou o romance em termos de reflexo da realidade: "Sua pretensão seria a de dar um espelho fiel quanto possível do homem e do mundo que o rodeia" (JOSEF, 1963, p. 14); finalmente, embora os exemplos pudessem ser muitos outros, Pedro Maligo falou de um "modo objetivo de descrição" (MALIGO, 1998, p. 23) no romance naturalista. A partir disso, é como se a descrição minuciosa das paisagens, o detalhamento do modo de vida de determinado personagem e a referência a lugares reais traduzisse uma apreensão direta dessa realidade, capacitando a narrativa ficcional até mesmo para ocupar o lugar da investigação histórica ou sociológica.

Sem que se negue as contribuições provenientes de tais abordagens (as quais de fato existem), entendo que seu questionamento pode oferecer uma nuance aos estudos sobre a literatura de caráter realista/naturalista, útil para iluminar alguns aspectos que nem sempre têm sido levados em consideração em sua abordagem. A assertiva de Lilian Furst, cujo livro All is true: the claims and strategies of realist fiction traz esclarecimentos importantes sobre o tema, me parece certeira:

Por um tempo surpreendentemente longo, mesmo em meados do século XX, a maioria dos críticos foi guiada em sua abordagem da ficção realista pelas instruções de leitura enunciadas pelos próprios romancistas. Ressaltando as afinidades entre a ficção e a vida cotidiana, eles estavam implicitamente subscrevendo a referencialidade como o modo apropriado de leitura. Se o romance realista foi por mais de um século a vítima de leituras simplistas, 
isso se deu porque críticos o tomaram por seu valor de face, aceitando a autoimagem que os realistas propagaram deles mesmos como meros cronistas dos seus dias (FURST, 1995, p. 13).

Basta considerar algumas das petições de princípio dos romancistas para se certificar de que ela tem razão. Tome-se como exemplar uma das mais célebres afirmações do escritor naturalista Émile Zola (1840-1902), segundo a qual o romance deve ser "uma página de mármore tirada de um bloco de realidade" (ZOLA, 1979, p. 104), sugerindo que seu trabalho enquanto escritor não fosse mais do que oferecer ao leitor uma porção da realidade tal e qual. O fato de o próprio Zola ter, alhures, conduzido sua própria reflexão em um sentido mais crítico quanto à presença da subjetividade no trabalho romanesco não foi seguido por alguns de seus críticos. O "valor de face" da proposta realista não foi, em algumas abordagens, problematizado, o que, no caso dessa literatura, prenhe de estratégias para transmitir a ideia de que o trabalho do autor foi feito à semelhança de um fotógrafo (imagem comum à época, que já traz em si a ideia de seleção e efeito, mas, não obstante, frequentemente evocada), resultou em uma abordagem algumas vezes benevolente demais (como se os autores realmente tivessem conseguido transmitir a realidade tal qual ela é, o que seria motivo de elogio), outras severamente críticas, mas pelos motivos errados (no caso de se acreditar que os autores agiram como meros narradores sem qualquer apreço pela elaboração literária). Posso mencionar aqui Flora Sussekind (1984), que trata o naturalismo como "ideologia estética" por supostamente procurar ocultar o trabalho linguístico presente em sua elaboração.

Lançadas algumas questões gerais, é hora de afunilar um pouco a discussão. No caso de Inglês de Sousa, gostaria de mostrar brevemente como História de um pescador, romance de 1876, revela, ao contrário da ideia de que seu autor ofereceu um relato meramente testemunhal ou objetivo da realidade amazonense, pontos de vista muito mais afeitos a um olhar exógeno (juntamente com seus valores) do que nativo sobre a localidade descrita. $\mathrm{O}$ romance se desenvolve a partir de José, filho de Anselmo e Benedita, casal sujeito ao capitão Fabrício Aurélio, de quem são devedores, e sua disposição em desposar Joaninha. José, no entanto, é pobre, e não tem meios de concorrer com o capitão Fabrício, que nutre o desejo de possuir a mesma jovem. Essa trama serve para que o romance explore questões relativas ao poder de que gozam os proprietários sobre os moradores pobres de suas terras e a impotência 
desses últimos advinda da ausência do cumprimento das leis e do prevalecimento da vontade do mais forte nas relações sociais.

Nesse enredo, destacam-se alguns momentos em que o narrador não sustenta o ideal de impessoalidade, lançando juízos de valor mais afeitos, como anunciei anteriormente, a um olhar exógeno sobre a sociedade das pequenas cidades amazônicas. Ele não esconde, por exemplo, certa indignação com o comportamento dos pescadores que se reúnem anualmente na localidade chamada Lago Grande para exercer seu ofício. O que chama sua atenção é a disposição deles em largarem tudo para comparecerem a esse evento: "Não podeis ajuizar do entusiasmo, do verdadeiro delírio da gente pobre do Amazonas pelo Lago Grande, e outros lugares de pesca. Não há ninguém que não queira ir. Até mulheres, famílias inteiras, partem, que nada lá têm que fazer, partem, abandonando o sítio” (SOUSA, 1990, p. 94). Não se trata apenas de descrever o entusiasmo, mas de avaliá-lo explicitamente: "Se algum, mais ajuizado, achando-se em condições vantajosas, resiste por algum tempo à tentação, vêm os outros chamá-lo, e só o ver passar uma por uma aquela multidão de montarias, cheias de gente alegre e festiva, fá-lo mudar a primeira resolução" (SOUSA, p. 94, grifos meus). A ocasião se mostra cheia de "gente alegre e festiva" dirigindo-se a um local de celebração, mas ela é avaliada como "tentação" e coisa de gente sem juízo.

De maneira semelhante, há ainda sobre o tapuio, que habita as regiões ribeirinhas e as pequenas vilas amazônicas, uma visão predominantemente negativa. Note-se a generalização: "Os tapuios do Amazonas quando trabalham para os outros, e quando não estão sob as vistas do amo, são de uma incúria, um descuido notáveis. Assim é que a gente do capitão parecia em viagem de recreio" (SOUSA, 1990, p. 127). Diante do sítio de Gonçalo Bastos, descrito como limpo e ocupado por plantações de tabaco e banana, o elogio é feito em contraposição ao tapuio: "tudo isto denotava que o sítio não era tratado por algum tapuio indolente e pouco amestrado" (SOUSA, p. 163), e o próprio Gonçalo, ao se instalar no sítio, "poucas visitas recebia porque pouco tempo tinha para dispensar aos vadios dos arredores" (SOUSA, p. 164). O tapuio, finalmente, é de "índole vaidosa e inchada" (SOUSA, p. 198), o que invalida a ideia que o narrador faz de si ao dizer que "eu não faço comentários. Narro apenas o que sei” (SOUSA, p. 199).

Não estou interessado em elaborar um juízo moral sobre as opiniões emitidas pelo narrador. Apenas quero destacar que ele está longe de se constituir em um observador neutro e objetivo daquilo que descreve, como se seu olhar não fosse vazado por um conjunto de valores que, inevitavelmente, constrói determinado objeto de tal ou qual modo. Furst afirma que “A 'natureza do meio em si mesmo' requer que ao artista seja conferido o direito de 
selecionar, combinar, moldar o material; em suma, criar, mais do que copiar" (FURST, 1995, p. 5). Essa observação está ausente em grande parte dos comentários sobre a prosa ficcional de Inglês de Sousa. O gesto de escrever sobre algo envolve necessariamente uma operação de recorte de foco, escolha de palavras, construção de sentido, tudo o que impossibilita a ideia de cópia. Mas, frequentemente, esse é o termo que se sobressai em várias abordagens críticas, e não com o sentido de examinar o efeito de neutralidade ou "cópia" presente na elaboração literária, mas como se se tratasse de cópia mesmo.

Um outro elemento pode ser acrescentado ao que vimos tratando. Ele pode ser evidenciado quando nos damos conta de que o romance de Inglês de Sousa trabalha com tropos comuns ao que Leslie Wylie chama de novela de la selva. ${ }^{3}$ Essa menção coopera com a ideia de que o chamado romance amazônico confere determinados sentidos à floresta que não se configuram como uma abordagem objetiva. Em romances como Green Mansions (da autoria de William Henry Hudson [1841-1922], publicado em 1904), a floresta aparece como espaço de libertação das convenções cotidianas e fonte de "iluminação espiritual". Ao mesmo tempo, a apresentação que o personagem Abel faz da floresta "não apenas celebra a natureza como um asilo espiritual contra os assaltos da modernidade, como também é infundida com motivos imperiais de propriedade" (WYLIE, 2009, p. 99). Além disso, a visão idealizada dos índios teria um precedente literário nos Discursos de Jean-Jacques Rousseau (1712-1778) e seu Nobre Selvagem. No caso de Inglês de Sousa, um romance como $O$ missionário, se não idealiza os índios ao não poupar a tribo Mundurucu das descrições que apontam para grandes crueldades, assemelha-se à visão da floresta como espaço de libertação das convenções sociais: "Naquela região inteiramente despovoada e sujeita às correrias dos índios bravos, entrava de repente num mundo novo, longe da vida social" (SOUSA, 1998, p. 178). A floresta aparece como um lugar de revelação da verdade do personagem sobre si mesmo, no qual ele dá vazão ao que fora reprimido na vida na cidade:

Ia, enfim, achar-se face a face com a grande e virgem natureza, num tête-⿳亠丷⿵冂tête misterioso, em que poderia desabafar as dores secretas do coração dilacerado por sentimentos incompreensíveis; pensar e falar sinceramente, pondo o peito a nu, reconhecer-se a si próprio, ser franco consigo mesmo, propondo e resolvendo com lealdade, despido de todos os preconceitos, de todos os prejuízos de educação e de doutrina, o até ali insolúvel problema da natureza humana (SOUSA, 1998, p. 180).

\footnotetext{
europeia sobre os trópicos".

${ }^{3} \mathrm{Na}$ definição de Wylie (2009, p. 3), novela de la selva "denota romances da América Espanhola distinguidos por seu recurso à floresta não apenas como espaço físico, mas também como símbolo para os limites da escrita 
É como se, na floresta, o homem fosse mais naturalmente homem, e a sensualidade fosse despertada como jamais pudesse ocorrer em outro ambiente:

O gozo se tornava necessário e fatal; conveniências do estado, crença religiosa, escrúpulos de homem honesto, tudo cedia ao seu imenso amor. Consumia-se em ardores estéreis, agarrado aos punhos da rede, numa ânsia louca de apertar nos braços um corpo fremente de mulher bonita, e desfalecia por fim, cansado, aborrecido, indignado, enjoado do cheiro a flor de castanheiro que o seu corpo exalava. Isto todas as noites! (SOUSA, 1998, p. 259).

Mais do que descrição objetiva, tais passagens reforçam tropos comuns na abordagem da floresta no romance realista. Nele também se nota, como na passagem acima, que a floresta define e consolida a masculinidade, o que acontece recorrentemente nas novelas de la selva. Não digo que Inglês de Sousa tenha lido tais novelas para compor seus romances, mesmo porque seu período de produção romanesca é anterior ao delas, mas sua abordagem deixa patente que o olhar que descreve a floresta lança mão de dispositivos literários para a criação de certos efeitos de sentido, reforçando, assim, certa continuidade ou recorrência dentro de uma tradição literária, mais do que se constituindo em exploração in loco de determinada realidade.

E foi justamente por conta dos temas tratados nos romances de Inglês de Sousa que houve uma associação deles com relatos de viajantes. De fato, é muito plausível que o autor tenha tido contato não só com os escritos produzidos pelos viajantes, mas com eles mesmos. Sobre o dia 27 de agosto de 1865, pode-se ler no diário da viagem do geólogo e biólogo suíço Louis Agassiz (1807-1873) pelo Brasil:

Na última noite nós paramos para recolher lenha na cidade de Óbidos, mas sem desembarcar; continuamos direto nesse porto, pelo lado sul do rio, na boca do rio Tupinambaranas. Aí fomos muito cordialmente recebidos pelo Dr. Marcos, um velho correspondente do Sr. Agassiz, quem por várias vezes enviou espécies do Amazonas para o Museu de Cambridge. (...) Passamos um dia muito agradável ontem na casa do Dr. Marcos (AGASSIZ, 1868, p. 171).

"Dr. Marcos" é muito provavelmente o pai de Inglês de Sousa, que, com onze ou doze anos nessa época, pode ter guardado perenemente a lembrança de viajantes estrangeiros, vindo a utilizar seus escritos para a composição de seus próprios romances. Uma das propostas mais claras de comparação entre romance e relato de viagem é feita por Mauro Viana Barreto (2003), que mostra de modo eloquente passagens semelhantes em um e outro registro. Noto, no entanto, nessa abordagem, a tendência em se tomar os relatos de viajantes como uma espécie de contrapartida não ficcional capaz de confirmar a veracidade do relato ficcional do romancista: "Pelo testemunho de Henry Bates fica-se sabendo que esse episódio

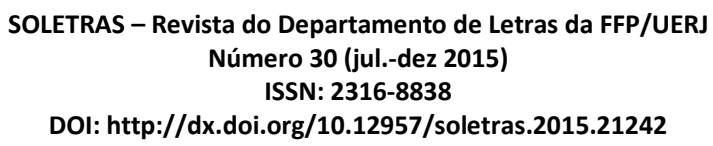


ficcional não era uma prática incomum na vida real cotidiana do Baixo Amazonas" (BARRETO, 2003, p. 171). Acho que a posição precisa ser matizada.

Uma vista d'olhos em alguns poucos exemplos deixa patente que a visão do viajante sobre determinada realidade é também carregada de avaliações - e não podia ser diferente. Em artigo em que discute a imagem que viajantes fazem de aspectos da cultura letrada no Brasil (cenas de leitura, o número de livrarias, o estado das escolas etc.), Márcia Abreu mostra o quanto o olhar do estrangeiro, muitas vezes usado como fonte confiável sobre a sociedade brasileira do passado, está condicionado pelas referências das altas esferas culturais de onde geralmente partiam para suas investigações em terras distantes e desconhecidas: "Sua forma de ver e de avaliar o mundo é condicionada por sua inserção na alta cultura europeia, assim como a da maior parte de seus leitores, já que o público-alvo dessas obras era também europeu" (ABREU, 2006, p. 93). Essa é uma boa deixa para pensarmos em alguns excertos reveladores do peso da bagagem cultural do viajante ao relatar o que vê, no caso em tela, no interior da Amazônia.

Henry Walter Bates (1825-1892), naturalista inglês que esteve no Brasil em 1848, escreve a certa altura de seu relato sobre os habitantes: "A gente desses lugares parecia estar acima dos trabalhos assalariados. São naturalmente indolentes e, além disso, possuem todos pequenas plantações suas, que lhes dão para viver com certa independência" (BATES, 1944, p. 157, vol. I). A única forma de vencer a "indolência", na opinião de Bates, é por meio do trabalho assalariado, não pelas pequenas plantações que possibilitavam "viver com certa independência", mesmo porque a simples subsistência não parece ser suficiente como ideal de realização, pois "a preguiça e desmazelo incorrigíveis do povo impedem que ele se cerque de todas as riquezas de uma região tropical, como certamente fariam os inteligentes fazendeiros europeus" (BATES, 1944, p. 297, vol. I). "Inteligentes fazendeiros europeus" que certamente não se sujeitariam a servir de mão de obra a outrem, gesto que seria prontamente valorizado por Bates. Quando, no entanto, a recusa ao trabalho manual parte do nativo da floresta, isso é motivo para que ele seja visto como orgulhoso: "Era quase impossível obter quaisquer empregados em Santarém; a gente livre era muito orgulhosa e não se alugava; os escravos eram muito poucos e indispensáveis aos seus senhores, para ser cedidos aos outros" (BATES, 
1944, p. 7, vol. II). De resto, Bates não faz nenhuma questão de esconder o fato de que seu olhar foi moldado pela suposta superioridade de seus gostos e inteligência:

Era natural que me sentisse atemorizado ante a perspectiva de uma mudança tão grande, mas agora, passados três anos de renovada experiência da Inglaterra, sinto como a vida civilizada, onde o nosso sentir, os nossos gostos e a inteligência encontram abundante nutrição, é incomparavelmente superior à esterilidade espiritual de uma existência semisselvagem, mesmo quando passada nos jardins do Éden (BATES, 1944, p. 398, vol. II).

Minha crítica não se dirige ao etnocentrismo de Bates que, claro, pode ser levada a cabo, mas ao valor de verdade dado ao relato de viagem. Algo semelhante acontece no caso de Alfred Russel Wallace (1823-1912), biólogo, geógrafo e antropólogo inglês que também escreveu um relato de sua viagem pelo Brasil na década de 1840, quando fala da "escassez de trabalho ou indolência do povo", que está rodeado de pés de café, mas não recolhe senão "um pouco para consumo privado" (WALLACE, 1969, p. 8), revelando, assim, certa dificuldade em compreender um sistema de vida que não se preocupe em acumular além do necessário à subsistência.

Ao reunirmos esses trechos dos relatos de viajantes com as passagens destacadas alhures de História de um pescador, notamos a semelhança na abordagem do habitante nativo da região, em ambos os casos inclinada a tomá-los como indolentes, preguiçosos e irresponsáveis, sempre deixando patente que há um julgamento sobre a cultura local e não somente a tentativa de descrevê-la sem a interferência da subjetividade. Esses elementos ensejam a exploração da dicotomia anunciada no início do artigo, entre, grosso modo, estruturalismo e mimetismo.

\section{4}

Até aqui temos, portanto, o exemplo de uma composição ficcional de corte realista, relatos de viagem, que não são compostos nem sob um caráter ficcional nem a partir de procedimentos historiográficos, e uma realidade que é o alvo de ambos retratar, a de diferentes ambientes que compõem a Amazônia em finais do século XIX. Entendo que a relação entre esses textos permite discutir alguns aspectos caros aos estudos literários concernentes a questões como o valor de verdade da composição literária e a relação entre determinada realidade e sua elaboração ficcional.

Antes de continuar, é importante deixar claro o lugar em que me coloco para fazer essa discussão. Se retornarmos às primeiras menções aos romances de Inglês de Sousa na 
imprensa, veremos que as questões aqui abordadas não estavam presentes em nenhuma delas. Em finais do XIX, havia a expectativa de que um romance realista, de fato, fosse reflexo fiel de determinada realidade, e muitos deles foram tomados como fontes fidedignas de conhecimento, seja sobre o passado, seja sobre regiões remotas pouco visitadas pelos habitantes dos centros urbanos mais populosos. Apenas à guisa de exemplo, lembro que Souza Bandeira (1865-1917), membro da Academia Brasileira de Letras, em artigo publicado na Revista Brasileira em 1899, lançou a expectativa de que o romance $O$ missionário, de Inglês de Sousa, respondesse a uma questão própria da realidade social em que ele, Bandeira, viveu, qual seja, se os religiosos de sua época ainda mantinham a disposição de enfrentar as mais árduas dificuldades em nome do exercício da vocação. A resposta à pergunta ele encontra no romance de Inglês de Sousa: "é um estudo desta natureza que se propõe fazer o Dr. Inglês de Sousa, no seu livro $O$ missionário, de que com o esmero e nitidez do costume a casa Laemmert acaba de dar uma segunda edição" (BANDEIRA, 1899, p. 114). Toma-se o romance como "estudo", proveniente de observação de uma realidade, não como elaboração própria de imaginação do escritor. Esse exemplo me permite lembrar que um é o projeto de recuperar as convenções de leitura em voga quando da publicação dos romances de Inglês de Sousa; outro, que é o que proponho aqui, é o de discutir criticamente certa convenção avaliativa que atravessou todo o século XX e chegou ao século XXI, abordando sua prosa ficcional como, de algum modo, relato objetivo, reflexo da realidade ou documento sobre a Amazônia de final do século.

Vou partir novamente de algumas afirmações de Mauro Viana Barreto sobre a prosa ficcional de Inglês de Sousa, porque, não obstante sua grande utilidade na associação que propõe entre os romances do autor paraense e a realidade amazonense do período, além da aproximação que propõe entre a ficção do escritor e relatos de viagem, elas se me afiguram emblemáticas de algumas noções muito comuns no estudo da literatura realista/naturalista que devem ser questionadas. De modo resumido, a leitura "socioantropológica" proposta por Barreto se apoia na ideia de que os romances de Inglês de Sousa comporiam um "documentário exato" da vida amazônica, até porque o autor "não escrevia seus romances pretendendo fazer apenas ficção, mas também esperava que espelhassem a realidade da forma mais exata possível" (BARRETO, 2003, p. 77). Isso tornaria o romance uma "fonte confiável sobre essa mesma realidade" (BARRETO, 2003, p. 201), borrando, assim, a distinção entre "literatura e crítica social, arte e ciência e (...) romance e antropologia" (BARRETO, 2003, 202). 
Há uma noção de reflexo em operação nessas avaliações, a qual está presa ao paradigma da mímese como tentativa de reprodução da realidade, como se o romancista fosse alguém que se localizasse na posição de observador externo do mundo. Lilian Furst, em seu indispensável livro sobre as "alegações e estratégias da ficção realista", problematiza a ideia de mímese aplicada ao romance realista, na medida em que ela favoreceu sobremodo uma leitura por vezes simplista dessas obras ao relegar a segundo plano seu caráter de elaboração linguística. $\mathrm{O}$ ideal de descrever as cenas de maneira sóbria, evitar rebuscamentos desnecessários de linguagem, procurar se ater a uma certa sequência no encadeamento dos enredos conduziu muitas vezes à tomada da prosa realista como trabalho ingênuo, que não exigiria, proporcionalmente, um esforço de leitura mais sofisticado. Furst se volta contra essa noção:

Um primeiro passo é remover a qualificação "simples" para reconhecer que ler ficção realista não é de modo algum uma tarefa tão simples e fácil como costuma ser assumido. Após ser por muito tempo tratado como um tipo de gênero do jardim da infância, no qual um benigno narrador ingenuamente desenvolve uma cativante história para um acolhedor círculo de aquiescentes leitores, o realismo tem ultimamente sido reconhecido como uma forma de arte muito mais intensamente elaborada do que aparenta ao olhar desprevenido (FURST, 1995, p. 22).

O fato de a prosa ficcional de Inglês de Sousa ter sido ambientada em um local real, cujo nome remete a regiões localizáveis no mapa, é um poderoso recurso na criação do "efeito de realidade", o qual, no entanto, parece ter suplantado a noção de que sua menção nos contos e romances remete antes a uma série de procedimentos artísticos mobilizados em sua criação do que a uma narrativa com pendores historiográficos. Isso não quer dizer, como já mencionei anteriormente, que o exercício crítico desprezará o local de ambientação do romance, pelo contrário: ele se perguntará pelo efeito de sentido que essa obra pode ter tido em seu momento de produção, pelos motivos que levaram a ressaltar alguns aspectos (como a disputa política na região) e não outros (digamos, o dia a dia dos escravos nas fazendas de cacau), como ele trabalha as convenções do gênero romanesco ao ambientar a trama fora de um grande centro urbano, que imagem dos índios, das diferentes classes sociais, de diferentes agentes sociais, tais como coronéis e padres, se depreende do romance etc. A tentativa de responder a essas questões, no entanto, difere da tomada do romance como "documento" sobre a realidade ou "reflexo" da realidade amazonense.

Gostaria, mais uma vez, de conceder a palavra a Lilian Furst, que volta ainda sua crítica justamente à tomada da ficção como história, gesto cuja tendência é a de desprezar a configuração estética da realização ficcional. Ela resume o que seria atentar para esse aspecto: 
(...) a configuração estética (...) é central para o modo alternativo de ler o passado na ficção realista no século XIX. $\mathrm{O}$ ato de recuperação aqui tem um impulso inteiramente diferente: ao invés de contemplar as alusões históricas como reflexos de uma realidade uma vez existente, ele procura reconhecer seu status representativo como sinais de contextualização. Esse é um modo de apreensão predominantemente literário, porque foca nas táticas gerais do discurso e seu impacto nos leitores, mais do que nos detalhes de acontecimentos específicos, ou mesmo na veracidade do relato. A ficção abarca materiais históricos, assimilando-os em sua construção ficcional (FURST, 1995, p. 81).

A partir de suas palavras, somos convidados a pensar que, mais que reflexo de determinada realidade, deve-se reconhecer na ficção sua tentativa de interpretar essa realidade a determinado público. Ela fará isso, como já dissemos, operando com as ferramentas à sua disposição, como a organização de um enredo, seu desenvolvimento em uma trama, a caracterização dos personagens, os desafios vivenciados por eles e o desenlace correspondente a cada um; assim, os sentidos possivelmente apreensíveis a partir desse modo de organização da narrativa ficcional são caros à análise literária, e não a correspondência entre o que é narrado e o que "de fato" aconteceu.

Outro equívoco bastante frequente na leitura de romances naturalistas/realistas é o que estabelece uma distinção entre um modo subjetivo e um modo objetivo de narrar. Posso recuperar essa distinção no estudo de Pedro Maligo sobre o romance amazônico, quando ele afirma que, nos primeiros romances de Inglês de Sousa, a Amazônia é "retratada muito objetivamente" (MALIGO, 1998, p. 32), enquanto, em romances posteriores, como $O$ missionário, as descrições seriam mais "subjetivas". Entendo estar presente nessa distinção uma divisão que, na verdade, não existe. Ela poderia se dar entre efeitos proporcionados por determinada forma de narrar, os quais, certamente, poderiam buscar um ideal de impessoalidade de um narrador que se limitasse a procurar descrever determinado objeto com minúcia, interessado em omitir ao máximo sua dicção própria, como se o objeto mesmo se colocasse diante do leitor de maneira imediata. Haveria aí, portanto, uma estratégia narrativa visando a um efeito de objetividade. E, por outro lado, poderia haver uma narrativa interessada em ressaltar a subjetividade do narrador, seu olhar próprio, realçando a parcialidade ou o interesse explícito em alcançar determinado sentido. Em ambos os casos, no entanto, o que está em questão são operações subjetivas, na medida em que partem de um sujeito que não pode se eximir da necessidade de fazer escolhas (vocabulário, foco narrativo, eleição e omissão de aspectos da realidade etc.). Furst, novamente, serve com precisão ao que venho apontando aqui: 
Se o alvo da ficção realista afirma ser mimético, isso significa não apenas que ela "precisa ser assim", mas, na verdade, que ela não pode ser outra coisa que não poética (em sentido amplo), porque a escrita realista não é menos um artefato estético do que a escrita romântica ou outras modalidades, e que ela tem suas próprias convenções, da quais a maior é uma dissimulação dessas próprias convenções em uma pretensa simplicidade (FURST, 1995, p. 190).

Nesse sentido, quanto mais bem empregada a convenção realista, maior o efeito de objetividade e neutralidade por ela transmitida, o que revelaria, na verdade, um trabalho subjetivo ainda mais apurado por parte de quem a pratica, porque indicador de domínio de uma arte e execução calculada de seus procedimentos.

Mas parte considerável de sua fortuna crítica, quando falamos do romance amazônico e mesmo da literatura naturalista/realista de forma geral, trouxe à baila uma questão intrincada nos estudos literários, a respeito da possibilidade de verdade da ficção. Como vimos nas considerações de Souza Bandeira sobre $O$ missionário, havia a convicção de que o romance veiculava verdades sobre aquilo que era objeto de sua narração. Quando se trata da literatura naturalista/realista, essa questão parece estar presente de uma forma ou de outra. ${ }^{4}$ Entendo que um mérito desse problema é o de chamar atenção para a relação entre o texto e a realidade, que, durante muito tempo, pendeu para um lado só, como se não houvesse nada além de textos. O livro de Garry Potter, The bet: truth in science, literature and everyday knowledge, com quem dialogaremos doravante, se opõe a essa tendência:

Há uma ampla linha de pensamento que reduz o problema do conhecimento à análise social das relações de poder ou à análise da linguagem. $\mathrm{O}$ relativismo que emerge dessas posições extremas não meramente historiciza o conhecimento mas torna-o a priori inviável para julgar comparativamente entre explicações concorrentes (POTTER, 1999, p. 16-17).

Endossando a crítica, enfatizamos aqui o caráter de construto estético da prosa realista e a mobilização de convenções capazes de criar um efeito de real, mas não descuramos de outro aspecto do realismo, que é sua relação com determinada realidade. Esse outro aspecto pode ser esclarecido na trilha da argumentação do mesmo Garry Potter, que parte da defesa de uma "asserção ontológica de uma realidade que existe independentemente de qualquer observador

\footnotetext{
${ }^{4}$ Vale a lembrança de que o último livro de Hayden White, The practical past, lançado em 2014, aposta suas fichas muito mais no que ele chama de "romance modernista" do que na própria historiografia quando se trata de trazer aspectos do passado à consciência do presente. 
(ou, para pôr de outro modo, independentemente de percepção ou crenças)" (POTTER, 1999, p. 1). No caso que vimos tratando, podemos nos aproveitar da hoje em dia não tão óbvia afirmação de Potter para defender a ideia de que existe uma Amazônia real onde se desenrolam os enredos da prosa ficcional de Inglês de Sousa. Ao situá-los em cidades que existem na realidade, ao tomar como base de suas tramas políticas uma configuração social existente contemporaneamente à escrita de seus romances, ao nomear tribos indígenas, como os Mundurucus, que de fato existiram na região norte do Brasil no século XIX (e existem até hoje), o escritor inevitavelmente partilha com seus leitores um fundo de referências que estão fora do romance. Sobre isso, Potter defende que "uma realidade compartilhada, e algumas relações compartilhadas com essa realidade, entre autores e todos os possíveis leitores, é simplesmente a condição de uma mínima eficácia comunicativa do texto" (POTTER, 1999, p. 146). Entendo que a afirmação está correta se tivermos uma expectativa desinflacionada sobre essa "realidade compartilhada"; para permanecermos ainda na questão do romance amazônico, é mister reconhecer que ele pode ter uma eficácia comunicativa mesmo para quem jamais pisou na Amazônia ou sequer ouviu falar dela. Por outro lado, é provável que o romance se revista de novos sentidos para quem, ao contrário, conhece tanto a Amazônia quanto os demais elementos relativos a ela abordados no romance. Nesse segundo caso, o romance desencadearia uma série de associações com a realidade que não estariam presentes no horizonte de uma leitura limitada apenas às relações internas propostas por ele.

Potter vai além, ao dizer que a justificativa para o exercício da crítica literária é a produção de conhecimento, não apenas de textos, mas do mundo. Essa é uma afirmação bastante ousada, com a qual concordariam os exemplos acima que tomaram a prosa ficcional de Inglês de Sousa como "documento" para a base de afirmações sociológicas sobre a Amazônia. Para Potter, um romance como Bleak House (1852), de Charles Dickens (18121870), permite ver mais do que o que o próprio autor ou seus contemporâneos podiam ver sobre a Inglaterra vitoriana. Mutatis mutandis, é como se disséssemos que pela leitura de romances como $O$ missionário e $O$ cacaulista, entre outros, poderíamos conhecer a Amazônia de uma maneira diferente daquela de seus próprios habitantes. Confrontado com a pergunta a respeito de que tipo de conhecimento é oferecido pela literatura, Potter responde:

Eu poderia apenas responder que ele está apenas lá, nas palavras de Dickens sobre a página. Ele experimentou, observou, pensou. Ele processou (e não em um vácuo) seus pensamentos, observação e experiência, e assim produziu conhecimento na forma diferente de um romance. Ser capaz de articular esse conhecimento de uma maneira diferente, na forma de proposições científicas sobre a natureza da realidade, seria produzir novo conhecimento (POTTER, 1999, p. 189). 
Potter, portanto, defende a ideia de que a literatura pode produzir conhecimento, mas que ele não é traduzível em termos diferentes daqueles que comparecem na elaboração linguística do romance. Isso, no entanto, seria um procedimento semelhante ao que fora criticado pelo próprio Potter em relação ao estruturalismo, que, para ele, nega a realidade em prol das relações estabelecidas pelo texto: se o conteúdo da página não pode ser expresso senão com as próprias palavras que formam esse conteúdo, o texto continuaria a manter um papel autônomo em relação à realidade em que ele pretensamente pretende atuar. Ciente desse problema, Potter continua:

Tradução, como disse Derrida, é transformação. Nesse caso, a tradução/transformação seria tomar o conhecimento articulado em uma forma literária e não meramente apresentá-lo em uma forma diferente, isto é, não ficcional; mas utilizar certos conceitos para extrair e rearticular o que está no texto de Dickens, e simultaneamente integrar isso em um sistema de conceitos que estavam indisponíveis para ele. Essa é a produção da crítica. Empenhar-se nisso corretamente é produzir mais do que um conhecimento do texto, mas também produzir um conhecimento maior do que aquele que já é um conhecimento dentro do texto (POTTER, 1999, p. 189).

Infelizmente, Potter não oferece um exemplo de quais conceitos seriam extraídos do texto e rearticulados em um conjunto novo, proveniente, segundo entendo a proposta, das condições atuais de produção de conhecimento que não eram as mesmas do autor no passado. Não obstante, ele fornece uma boa pista a respeito da questão do conhecimento produzido pela literatura ao permitir a inferência - que é o que faço aqui - de que a pergunta deve ser formulada de maneira adequada. Seria o caso, a partir disso, de repensar a própria pergunta quando a expectativa de resposta se dirige ao mesmo tipo daquela oferecida por campos como o da história, da sociologia ou da antropologia. Nela não se considera a especificidade da elaboração literária, a qual, como notou bem Potter, não pode ser meramente substituída por proposições científicas a respeito da realidade. Não se trata de esperar, portanto, por uma verdade concorrente entre a narrativa ficcional e a historiográfica (ou sociológica ou antropológica), nem pensar em uma verdade de correspondência, como se o romance fosse mais verdadeiro na medida em que mais fielmente retratasse determinada realidade. Isso seria se restringir a uma abordagem conteudística da literatura que não atentaria para sua especificidade formal. $\mathrm{O}$ grifo aqui apenas ressalta que a discussão, a partir desse momento, poderia se estender longamente, posto que, ao mencionar a questão da especificidade formal da literatura, não faço mais do que indicar a ponta de um iceberg, justamente quando o artigo deve ser finalizado. Que se tome isso, no entanto, como resultante do próprio tema que foi aqui abordado. Como querer tomar por encerrada sua discussão? 
Ademais, ela serve para calibrar o olhar quando a prosa ficcional de Inglês de Sousa for o objeto em discussão, pois, como vimos, muitas fichas foram apostadas na ideia de que a descrição da paisagem amazônica era tão mais valorizada quanto maior sua fidelidade com a "Amazônia real". Compreendemos o funcionamento desse efeito de real presente na descrição, mas somos capazes de perceber a construção literária que permite sua existência, o que deixa as coisas longe da simplicidade com que muitas vezes foi encarada a prosa naturalista/realista.

\section{Referências bibliográficas:}

ABREU, Márcia. Apatia, ignorância e desinteresse. Revista do Programa de Pós-Graduação em Letras da Universidade de Passo Fundo. Passo Fundo, RS: Universidade de Passo Fundo, vol. 2, n. 1, p. 83-98, jan./jun. 2006.

AGASSIZ, Louis. A journey in Brazil. Boston: Ticknor and Fields, 1868.

BAGULEY, David. Le naturalisme et ses genres. Paris: Éditions Nathan, 1995.

BANDEIRA, J. C. de Souza. O padre catholico e a catechese. Revista Brasileira, tomo XX, 1899, p. 109-127.

BARRETO, Mauro Viana. O romance da vida amazônica: uma leitura socioantropológica da obra literária de Inglês de Sousa. Presidente Venceslau, SP: Letras à Margem, 2003.

BATES, Henry Walter. O naturalista no Rio Amazonas. Trad., Prefácio e Notas Candido de Mello-Leitão. São Paulo: Companhia Editora Nacional, 1944.

FURST, Lilian R. All is true: the claims and strategies of realist fiction. Durham: Duke University Press, 1995.

GREENBLATT, Stephen. Rennaissance self-fashioning: from More to Shakespeare. Chicago: The University of Chicago Press, 2005.

JOZEF, Bella. Apresentação. In: Inglês de Sousa: textos escolhidos. Rio de Janeiro: Livraria Agir Editora, 1963.

MALIGO, Pedro. Land of metaphorical desires: the representation of Amazonia in Brazilian Literature. New York: Peter Lang, 1998.

MOISÉS, Massaud. História da literatura brasileira, v. II: Realismo e Simbolismo. 5. ed. São Paulo: Cultrix, 2001.

POTTER, Garry. The bet: truth in Science, literature and everyday knowledges. Vermont: Ashgate Publishing Company, 1999. 
RIFFATERRE, Michael. Fictional truth. Baltimore; London: Johns Hopkins University Press, 1990.

SOUSA, Inglês de. O missionário. Rio de Janeiro: Topbooks, 1998 [1888].

SOUSA, Inglês de (Luiz Dolzani). História de um pescador: cenas da vida do Amazonas. 2. ed. Belém: Fundação Cultural do Pará Tancredo Neves; Secretaria de Estado da Cultura, 1990 [1876].

SPELLMEYER, Kurt. Travels to the Heart of the Forest: Dilettantes, Professionals, and Knowledge. College English, vol. 56, n. 7, p. 788-809, Nov. 1994.

SUSSEKIND, Flora. Tal Brasil, qual romance? Uma ideologia estética e sua história: o naturalismo. Rio de Janeiro: Achiamé, 1984.

THOMPSON, Edward Palmer. The poverty of theory \& other essays. New York: Monthly Review Press, 1978.

WALLACE, Alfred Russel. A narrative of travels on the Amazon and Rio Negro, with an account of the native tribes, and observations on the climate, geology, and natural history of the amazon valley. 2. ed. New York: Haskell House Publishers Ltd, 1969 [1853].

WYLIE, Lesley. Colonial tropes and postcolonial tricks: rewriting the tropics in the novela de la selva. Liverpool: Liverpool University Press, 2009.

ZOLA, Émile. O romance experimental e o naturalismo no teatro. Trad. Ítalo Caroni e Célia Berrettini. São Paulo: Perspectiva, 1979.

\title{
"Reality" in the naturalist novel: theoritical questions of a comparative approach
}

\begin{abstract}
This article addresses Inglês de Sousa's novel and the discussions raised by its critical reception to discuss strategies of realist/naturalist literary composition and its pretension of accuracy between the narration and its object. We try to take into account the contributions from the work of Lilian Furst and Garry Potter to advance this debate and raise questions regarding the status of truth in prose with this characteristic.
\end{abstract}

Keywords: Naturalist literature. Inglês de Sousa. Representation.

Recebido em: 10 de outubro de 2015.

Aprovado em: 15 de dezembro de 2015 . 